\title{
FAMÍLIA E INSERÇÃO LABORAL DE JOVENS MIGRANTES NA INDÚSTRIA DE CONFECÇÃO
}

\author{
Patrícia Tavares de Freitas*
}

\begin{abstract}
Neste artigo, abordamos os percursos sociais de jovens bolivianos e bolivianas que, em algum momento de suas vidas, migraram para se inserir em pequenas oficinas de costura de seus compatriotas, nas cidades de São Paulo, no Brasil, e Buenos Aires, na Argentina. A análise, baseada em pesquisa de doutorado intitulada "Projeto costura", busca abordar os vários sentidos atribuídos ao papel da família em suas formas de inserção, circulação e saída dessa atividade nas cidades de destino e na própria Bolívia.
\end{abstract}

Palavras chave: migração boliviana, juventude, indústria de confecção, trabalho. ${ }^{1}$

Os processos de globalização contemporâneos, engendrados a partir do final da década de 1970, concomitantes ao recrudescimento da competitividade comercial e às dinâmicas de reestruturação produtiva, vêm incidindo de diversas formas nos mercados laborais dos grandes centros urbanos, destacando-se o retorno dos denominados sweatshops ${ }^{2}$, no interior de amplos circuitos de subcontratação ${ }^{3}$.

* Doutora do departamento de sociologia do Instituto de Filosofia e Ciências Humanas (IFCH), da Universidade de Campinas (Unicamp). Torrinha - SP/Brasil.

1 Este artigo é parte da pesquisa de doutorado, "Projeto Costura: percursos sociais de trabalhadores migrantes, entre origens e destinos", financiado pela Fapesp (Fundação de Amparo à Pesquisa), no âmbito do projeto temático Fapesp "Observatório das Migrações do Estado de São Paulo (fases e faces do fenômeno migratório no Estado de São Paulo)".

2 Termo utilizado inicialmente durante o final do século XIX e início do século XX para descrever as condições de instalação e de trabalho precárias das pequenas oficinas de costura daquela época (GREEN, Nancy. Du sentier à la $7^{a}$ avenue: la confection et les immigrés, Paris - New York (1880-1980)).

3 PORTES, Alejandro e SASSEN-KOOB, Saskia. Making it underground: comparative material on the informal sector in western market economies; PALPACUER, Florence. Subcontracting networks in the New York city garment industry: changing characteristics in a global era; ROSS, Robert J. S. The new sweatshops in the United States: how new, how real, how many and why?; BONACICH, Edna e APPELBAUM, Richard. The return of the sweatshop. 
Nas cidades de São Paulo e Buenos Aires, essas transformações mais gerais começaram a se consolidar a partir dos anos 1990, década marcada pela abertura comercial e pela implementação de políticas socioeconômicas neoliberais. Nesse contexto, a indústria de confecção dessas cidades passou por uma profunda crise, com o fechamento de plantas industriais tradicionais e a dinamização de processos de reestruturação produtiva, produzindo o recrudescimento da exploração da força de trabalho e da precarização e informalização das condições de trabalho ${ }^{4}$.

A inserção de migrantes - principalmente de bolivianos e bolivianas -, na indústria de confecção desses dois importantes centros urbanos latino americanos, é considerada um dos exemplos extremos desses processos de precarização da força de trabalho ${ }^{5}$.

Conforme se depreende das inúmeras matérias veiculadas pela imprensa local dessas duas cidades, as oficinas de costura - cujos donos são, em sua maioria, os próprios migrantes - encontram-se, em muitos casos, fora dos padrões de higiene e de segurança mínimos definidos pelas legislações locais ${ }^{6}$, além de acumularem, no mesmo espaço das oficinas de costura, as funções de moradia e de alimentação desses migrantes. Concomitante a

${ }^{4}$ CRUZ-MOREIRA, Juan Ricardo. Industrial upgrading nas cadeias produtivas globais: reflexões a partir das indústrias têxtil e do vestuário de Honduras e do Brasil; GARCIA, O. L. Avaliação da competitividade da indústria têxtil brasileira; GARCIA, Renato e CRUZ-MOREIRA, Juan. O Complexo Têxtil Vestuário: um cluster resistente; GORINI, Ana Paula Fontenelle. Panorama do setor têxtil no Brasil e no mundo: reestruturação e perspectivas; HIRATUKA, Celio e GARCIA Renato Castro. Impactos da abertura comercial sobre a dinâmica da indústria têxtil brasileira; BENENCIA, Roberto. El infierno del trabajo esclavo - la contracara de las "exitosas" economías étnicas; LUPATINI, Márcio P. As transformações produtivas na indústria têxtil do vestuário e seus impactos sobre a distribuição territorial da produção e a divisão do trabalho industrial.

5 AZEVEDO, Flávio Antônio Gomes. A presença de trabalho forçado na cidade de São Paulo - Brasil/ Bolívia; BASSEGIO, Luiz. A imigração latino-americana para o Brasil: o caso dos bolivianos em São Paulo; BENENCIA, op. cit.; BEHERAN, Mariana e FREITAS, Patricia T. Trajetórias migratórias e inserção laboral de jovens migrantes bolivianos (as) em oficinas de costura nas cidades de São Paulo e Buenos Aires; BUECHLER, Simone. Sweating it in the Brazilian Garment Industry: Bolivian workers and global economic forces in São Paulo; CYMBALISTA, Renato e XAVIER, lara Rolnik. A Comunidade boliviana em São Paulo: definindo padrões de territorialidade; FREITAS, Patrícia T. e BAENINGER, Rosana. Imigração e cidade: origens e territórios da imigração boliviana para a cidade de São Paulo; BASTIA, Tanja. From mining to garment workshops - bolivian migrants in Buenos Aires; BASTIA, Tanja e McGRATH. Temporality, migration and unfreelabour: migrant garment workers; SILVA, Sidney A. Costurando sonhos - trajetória de um grupo de imigrantes bolivianos em São Paulo; IDEM. Bolivianos em São Paulo: entre o sonho e a realidade; KADLUBA, Ruth Camacho. A imigração na cidade de São Paulo - integração dos imigrantes na cidade como forma de combate à pobreza; CUSICANQUI, Silvia Rivera et alii. De chuequistas y overlockas - uma discussión en torno a los talleres textiles; MONTERO, Jeronimo. Neoliberal fashion: the political economy of sweatshops in Europe and Latin America.

6 Localizando-se, em geral, em lugares pouco iluminados e pouco ventilados, não sendo difícil flagrar instalações elétricas clandestinas para o funcionamento das máquinas de costura, o que constitui risco eminente de incêndios. 
essas condições precárias de instalação, destacam-se os intensos regimes de trabalho - com jornadas diárias de 15 horas ou mais - para o recebimento de remunerações inferiores às praticadas no mercado e, muitas vezes, pagas em espécie e não em moeda. Finalmente, há denúncias de situações de confinamento para o trabalho forçado e da presença de crianças e jovens submetidos a essas circunstâncias precárias e de intensa exploração laboral ${ }^{7}$.

Tendo em vista aprofundar a compreensão dessa realidade social, a partir do "ponto de vista da autonomia", conforme propõe Ma Mung8, destacando a perspectiva dos próprios migrantes, abordaremos a experiência social de jovens bolivianos e bolivianas que trabalham - ou o fizeram em um passado recente - em oficinas de costura nas cidades de São Paulo e/ou Buenos Aires, a partir de suas narrativas de vida. Focalizaremos, particularmente, seus percursos migratórios e laborais tendo em vista o papel da família em suas formas de inserção nessa atividade laboral.

Para o desenvolvimento dessas questões, o artigo será dividido em três seções: primeiramente, abordaremos o debate acadêmico sobre a inserção laboral de jovens migrantes. Posteriormente, serão apresentados, brevemente, alguns percursos migratórios e laborais de jovens bolivianos e bolivianas entrevistados em São Paulo e em alguns locais de origem dessa migração internacional na Bolívia. E, finalizaremos, com as análises desses percursos, tendo em vista destacar os vários sentidos que podem assumir a relações familiares em suas formas de inserção nas oficinas de costura das cidades de destino desses jovens migrantes.

\section{Inserção laboral de jovens migrantes no debate contemporâneo ${ }^{9}$}

De maneira geral, os estudos contemporâneos sobre a inserção laboral de jovens assinalam que, como consequência do progressivo aumento do desemprego mundial, a maior parte tem acesso a empregos instáveis, sem

\footnotetext{
Para fornecer alguns exemplos ilustrativos: em São Paulo, "Bolivianos são presos por trabalho escravo" (O Estado de São Paulo, 25 de julho de 1997), "Trabalho escravo avança em São Paulo" (O Estado de São Paulo, domingo, 17 de dezembro de 2006), "Zara reconhece trabalho irregular em 3confeccões de São Paulo (Folha online, <http://www1.folha.uol.com.br/mercado/961047zara-reconhece-trabalho-irregular-em-3-confeccoes-de-sp.shtml> (acesso em 19/09/2011). E em Buenos Aires, "Seis muertos por un incêndio en un taller têxtil de Caballito" (31 marzo de 2006, p. 12), "El drama de vivir como esclavos - testimonios de inmigrantes bolivianos que escaparon de talleres textiles ilegales" (La Nación, Sabado, 1 de abril de 2006), "Villa Lugano - rescatan 50 personas que vivian en dos talleres textiles clandestinos" (Clarin, 14 de abril de 2011), "Hubo incidentes trás allanamientos en ocho talleres textiles ilegales" (Clarin, 4 de junho de 2010).

8 MAMUNG, Emmanuel. Le point de vue de l' autonomie dans l'étude des migrations internationales: penser de I' intérieur lês phenomènes de mobilité.

9 Esta seção retoma um debate realizado em BEHERAN, FREITAS, op. cit.
} 
proteção social e com baixos salários. Esses estudos têm relatado, nesse sentido, a ocorrência de longos períodos de desemprego e precariedade laboral ${ }^{10}$.

E em relação aos habituais modos de socialização laboral, alguns autores consideram que elestambém se modificaram, no bojo desses processos de precarização do trabalho e desemprego prolongado, no período contemporâneo, com o desaparecimento da aprendizagem de um oficio no âmbito familiar ${ }^{11}$. Nesse sentido, da mesma forma que a crise econômica e o alto desemprego gerado a partir da consolidação do modelo neoliberal levaram a que muitos jovens não tenham conhecido - entre seus pais, mães e demais familiares - experiências vinculadas a empregos estáveis, tampouco são muitos os jovens cujos familiares se dedicaram a uma atividade laboral específica ao longo da vida.

Entretanto, a despeito dessa tendência de mitigação da influência da família nos processos de socialização laboral dos jovens em geral, no caso dos estudos sobre a inserção laboral de jovens migrantes, as relações de parentesco e os percursos laborais familiares seguem sendo importantes referenciais no momento de sua inserção nos mercados de trabalho, mesmo quando significados negativamente por esses mesmos jovens, conforme destacam uma série de pesquisas contemporâneas sobre a transição profissional desta população ${ }^{12}$.

No debate realizado na Espanha, enquanto, por um lado, Cachón Rodríguez ${ }^{13}$, aborda o que vai denominar de "trajetórias de vinculação familiar", em referência àquelas ligadas a empresas ou a atividades agrícolas de caráter familiar, por outro, Pedreño Cánovas e Castellanos Ortega ${ }^{14}$, abordam as intenções de "desidentificação" - a partir das quais os jovens migrantes buscam alcançar um capital simbólico distante das "etiquetas estigmatizantes" que recaem em seus pais e mães - que, ao final, dificilmente conseguem ser

${ }_{10}$ Nações Unidas, 2004 e OIT, 2004, apud BONFIGLIO, Juan et alii. Educación y trabajo. Un estudio sobre las oportunidades de inclusión de los jóvenes tras cuatro años de recuperación económica.

11 GALLART, María Antonia. Educación y empleo en el Gran Buenos Aires. 1991-1999; SALVIA, Agustín e TUÑON, lanina. Los jóvenes trabajadores frente a la educación, el desempleo y el deterioro social en la Argentina; FILMUS, Daniel et alii. La construcción de trayectorias laborales entre los jóvenes egresados de la escuela secundaria; JACINTO, Claudia. Políticas públicas, trayectorias y subjetividades en torno a la transición laboral de los jóvenes.

12 BEHERAN, Mariana. Niños, niñas y jóvenes bolivianos y bolivianas en la ciudad de Buenos Aires. Escolaridad y experiencias formativas en el ámbito familiar; BEHERAN, Mariana. Intersecciones entre trayectorias migratorias, escolares y laborales de jóvenes bolivianos y paraguayos residentes en un barrio del sur de la ciudad de Buenos Aires; PEDONE, Claudia. 'Lo de migrar me lo pensaría con calma': representaciones sociales de jóvenes en torno al proyecto migratorio familiar; MARTíNEZ, Jorge. Migración internacional de jóvenes de América Latina y el Caribe; TRPIN, Verónica. Aprender a ser chilenos. Identidad, trabajo y residencia de migrantes en el Alto Valle de Río Negro.

${ }^{13}$ CACHÓN RODRíGUEZ, Lorenzo. Inmigrantes jóvenes en España. Sistema Educativo y mercado de trabajo.

14 PEDREÑO CÁNOVAS, Andrés e CASTELLANOS ORTEGA, Mari Luz. En busca de un lugar en el mundo. Itinerarios formativos - laborales de los hijos de familias inmigrantes en el campo murciano. 
efetivadas por esses jovens, que acabam sendo incorporados precocemente ao mercado de trabalho, inserindo-se em dinâmicas de subproletarização.

$\mathrm{Na}$ América Latina e Caribe, Martínez ${ }^{15}$ analisou as migrações internacionais de jovens e sustenta que tanto na migração intraregional, como na emigração para os Estados Unidos, a maior parte dos migrantes jovens se encontram em situações de risco e vulnerabilidade. Estas circunstâncias obedecem às condições complexas em que esta população se encontra no âmbito educativo e laboral, bem como, algumas vezes, ao rápido trânsito à vida adulta e aos sentidos traumáticos decorrentes dessas experiências.

Na Argentina e no Brasil são praticamente inexistentes os estudos sobre esta temática, destacando-se o trabalho pioneiro de $\operatorname{Trpin}^{16}$, que analisou as experiências laborais de crianças e jovens chilenos e chilenas, no Vale Alto do Rio Negro, na Argentina, e de Beheran ${ }^{17}$, que analisou as experiências formativas que jovens migrantes bolivianos e bolivianas, paraguaios e paraguaias, residentes na cidade de Buenos Aires. De maneira geral, as autoras identificaram diversas formas de vinculação dessas crianças e jovens à experiência laboral e simbólica vivenciada por seus familiares adultos.

Essas vinculações de crianças e de jovens migrantes ou filhos de migrantes nascidos nas sociedades de destino aos percursos sociais de seus familiares, com reduzidas possibilidades de mobilidade social, refletem o contexto mais amplo de recepção dos denominados "novos fluxos migratórios"18. Em meio às transformações do capitalismo contemporâneo, esses migrantes não logram mais se inserir completamente nas estruturas socioeconômicas e culturais dos países de destino, como ocorria com as migrações internacionais do final do século XIX e começo do século XX, favorecendo, ao contrário, a manutenção dos vínculos com as localidades de origem e o estabelecimento de estruturas socioeconômicas próprias, os pequenos empreendimentos de migrantes, voltados para o abastecimento das próprias comunidades de origem ou para o mercado mais amplo que, de maneira geral, passaram a ser denominados de "economias étnicas"19.

\footnotetext{
${ }^{15}$ MARTÍNEZ, op. cit.

16 TRPIN, op. cit.

${ }^{17}$ BEHERAN, Intersecciones entre trayectorias..., op. cit; IDEM. Niños, niñas y jóvenes..., op. cit.

${ }^{18}$ ARANGO, Joaquim. Explaining Migration: a critical view; ASSIS, Gláucia de Oliveira e SASAKI, Elisa Massae. Novos migrantes do e para o Brasil: um balanço da produção bibliográfica; GREEN, op. cit.; GLICK SCHILLER, Nina et alii. From immigrant to transmigrant: theorizing transnational migration; POTOT, Swanie. Circulation et reseaux de migrants roumains - une contribution a l'etude des nouvelles mobilites en Europe.

${ }^{19}$ LIGHT, Ivan e GOLD, Steven. Ethnic Economies; BONACICH, Edna. A theory of middleman minorities; IDEM. The other side of ethnic entrepreneurship: a dialogue with Waldinger, Aldrich, Ward and associates.
} 
Em relação à inserção boliviana na indústria de confecção das cidades de São Paulo e/ou Buenos Aires, embora se trate de um trabalho inserido em circuitos de subcontratação mais amplos, nas pontas dos quais podemos encontrar grandes multinacionais, lojistas coreanos e autóctones, é um trabalho que se realiza em pequenas oficinas de costura de donos que são, em sua maioria, bolivianos e bolivianas ${ }^{20}$.

Conforme veremos nas próximas seções, essas circunstâncias intensificam as ambivalências do papel das redes de sociabilidade familiares na inserção dos jovens bolivianos e bolivianas nessa atividade laboral.

\section{Percursos migratórios e laborais de jovens migrantes}

Nesta seção, apresentaremos os percursos de vida de seis jovens bolivianos e bolivianas que, em algum momento de suas vidas, se inseriram na indústria de confecção das cidades de São Paulo e/ou Buenos Aires ${ }^{21}$.

Ângela - jovem de 19 anos, entrevistada na cidade de São Paulo, no Brasil $^{22}$. Nasceu em La Paz, em 1990, e também morou em Cochabamba, na Bolívia, antes de se mudar definitivamente para São Paulo, em 1994, quando tinha 4 anos. A mudança para São Paulo, com sua mãe e seus irmãos, se deu com o objetivo de reencontrar seu pai - que havia emigrado um ano antes e acabara de montar sua própria oficina de costura, depois de trabalhar como costureiro em outras oficinas na cidade. Em São Paulo, seus pais se separaram e sua mãe montou uma oficina de costura própria, no bairro do Bom Retiro. Quando terminou o colegial, por volta dos 17 anos, Ângela começou a trabalhar como costureira na oficina de costura de sua mãe, na qual trabalha até os dias atuais. Ângela, que já observava o trabalho realizado pela mãe ao longo da infância, somente aprendeu a costurar de fato quando começou a trabalhar com a mãe em sua oficina de costura. A mãe trabalha para lojistas coreanos e Ângela diz estar satisfeita com o trabalho, pois ganha o seu próprio dinheiro, além de ajudar sua mãe a conquistar mais coisas - agora, por exemplo, estão juntando dinheiro para comprar a casa própria.

${ }^{20}$ As oficinas de costura também podem ser de donos provenientes da Coreia do Sul, do Paraguai e do Peru. Entretanto, conforme verificamos ao longo da pesquisa de doutorado, a inserção boliviana inicial nessa atividade nas cidades de destino ocorre em oficinas de costura de outrosmigrantes bolivianos que, na maioria das vezes, conforme veremos, contratam seus trabalhadores na própria Bolívia. Ver: FREITAS, Patrícia. Projeto Costura: percursos sociais de trabalhadores migrantes, entre origens e destinos.

${ }^{21}$ Os casos apresentados constituem uma pequena amostra de um material mais amplo de entrevistasem profundidade, de narrativas de vida, realizadas no âmbito da pesquisa de doutorado em São Paulo (junto a migrantes inseridos na costura) e nos municípios de Cochabamba, La Paz, El Alto e Escoma (município rural do altiplano andino), com bolivianos e bolivianas que, em algum momento de suas vidas, migraram para trabalhar na indústria de confecção das cidades de São Paulo e/ou Buenos Aires, entre 2010 e 2013. Ao total foram entrevistados 18 migrantes em São Paulo e 32 migrantes, na Bolívia.

22 Todas as idades dos jovens entrevistados, referem-se à idade que tinham no momento em que foram entrevistados. 
Esteves - jovem de 21 anos, entrevistadona cidade de São Paulo, no Brasil. Nasceu na cidade de La Paz, Bolívia, em 1988. Emigrou para São Paulo, junto com os pais e dois irmãos, em 1998, quando tinha 10 anos. Os pais de Esteves emigraram para trabalhar na oficina de costura de seus tios e, com o tempo, montaram uma oficina de costura própria no bairro da Penha. Esteves não queria seguir a trajetória laboral dos pais e, por isso, seu primeiro trabalho, aos 17 anos, foi como entregador de panfletos e, depois, como office boy. Entretanto, depois que decidiu "amigar-se" com uma boliviana que acabara de engravidar, Esteves teve que se inserir no trabalho na oficina de costura dos pais. Esteves aprendeu a costurar por volta dos 17 anos, depois de finalizado o ensino secundário e, desde então, e até resolver amigar-se, Esteves fazia uns "bicos" na oficina dos pais, quando não conseguia outros trabalhos. Atualmente, Esteves mora (com sua mulher e filho) e trabalha na oficina de costura da família. Entretanto, diz não gostar do trabalho e está em busca de outro emprego.

Ester - jovem de 17 anos,entrevistadana cidade de São Paulo, no Brasil. Nasceu na cidade de La Paz, Bolívia, em 1992. E emigrou para São Paulo em 2009, trazida pelos tios que possuem uma oficina de costura na cidade. Ester ainda não terminou os estudos do ensino médio e disse que veio a passeio e com a possibilidade de "talvez" trabalhar como costureira na oficina de seus tios. O aprendizado do ofício se deu na oficina dos tios, assim que chegou a São Paulo, mas, a princípio, não tinha intenção certa de trabalhar, estava apenas aprendendo a costurar. Entretanto, depois que aprendeu a utilizar as máquinas, os tios a obrigaram a trabalhar na oficina deles. Ester não gostou do trabalho e quer voltar para a Bolívia, pois além de sua mãe estar doente, ela sente muitas saudades de seus pais. Entretanto, o tio não lhe dá dinheiro para voltar e diz que ela está lhe enganando e que se der o dinheiro, ela fugirá para outra oficina.

Diana - jovem de 22 anos entrevistada na cidade de Cochabamba, na Bolívia. Nasceu em Cochabamba em 1990. Alguns meses após o seu nascimento, sua família (pai, mãe e 12 irmãos) mudou para a cidade de Santa Cruz, na Bolívia, onde moravam os seus tios paternos. Após 8 anos, sua família retornou à Cochabamba, indo morar no bairro de Villa Pagador, na periferia da cidade, conhecido como o bairro da costura. Com uma mãe cozinheira e um pai costureiro, Diana começou a aprender a costurar junto com o pai quando tinha 9 anos e, aos 11 anos iniciava sua vida laboral como ajudante e, depois, costureira nas oficinas de costura de seu bairro. A migração para São Paulo foi realizada quando Diana tinha 20 anos, dois anos após finalizar o ensino médio, em 2010, convidada por uma prima que já trabalhava em uma oficina de costura no Brasil, quando de seu retorno para as festas de final de ano. A viagem de Diana foi financiada pela dona boliviana da oficina de costura em que sua prima trabalhava. No período de um ano em que passou trabalhando nessa oficina de costura, conseguiu juntar 5 mil dólares e, em seu retorno, montou um oficina de costura domiciliar na casa de seus pais. Diana afirma gostar muito do trabalho como costureira e considera que, embora o ritmo de trabalho fosse muito 
mais intenso em São Paulo, foi importante para que conseguisse se estabelecer profissionalmente na Bolívia.

Orlando - jovem de 22 anos, entrevistado na cidade de Cochabamba, na Bolívia. Nasceu em Cochabamba, em 1990 e, quando tinha 2 anos, sua mãe saiu de casa com o seu irmão mais velho. O pai de Orlando casou com outra mulher logo em seguida e ele acabou sendo criado por sua avó. Aos 8 anos começou a trabalhar como vendedor ambulante de refrescos e sorvetes e, depois, como ajudante de padeiro, abandonando os estudos após a finalização do ensino fundamental. Após a morte de sua avó, quando tinha 16 anos, em 2006, foi convidado para trabalhar na oficina de costura de sua prima em Buenos Aires, onde aprendeu a costurar. Além de trabalhar como costureiro, Orlando ajudava no cuidado de seus sobrinhos e, na baixa temporada, voltava para a Bolívia para convidar conhecidos para o trabalho na oficina de costura de sua prima. Embora fosse grato à sua prima pelo trabalho, se sentia explorado, pois trabalhava muito e ela passava meses sem pagá-lo. Orlando chegou até a mudar de oficina de costura em Buenos Aires, mas pela sensação de solidão e por considerar as instalações dessa oficina muito precárias, acabou retornando depois de dois meses à oficina de sua prima. Após 4 anos em Buenos Aires, em 2010, Orlando recebeu, pela primeira vez, notícias de sua mãe que estava, junto com o seu irmão, trabalhando em uma oficina de costura em São Paulo. Para encontrá-la, Orlando migra para São Paulo financiado para trabalhar na oficina de costura de um amigo de seu tio. Entretanto, após muitos desentendimentos, pois se sentia explorado por esse boliviano, muda para a oficina em que sua mãe trabalhava. O convívio com a sua mãe foi muito difícil e, após 6 meses, decide mudar novamente para a oficina de uma boliviana que contatou por meio de uma anúncio. Atualmente, Orlando mora em Guarulhos, nessa oficina de costura e se sente muito feliz com o salário e com o ambiente da oficina ${ }^{23}$. E o seu objetivo é permanecer em São Paulo mais alguns anos para juntar dinheiro suficiente para comprar um terreno na Bolívia e montar sua própria oficina de costura domiciliar.

\section{Trabalho, Família e migração na experiência social dos jovens costureiros}

Nos casos dos jovens bolivianos e bolivianas apresentados na seção anterior, as relações de sociabilidade familiares e de vizinhança mostraram-se centrais em seus percursos migratórios e em sua inserção inicial na costura, seja na Bolívia, seja nas cidades de destino da migração internacional. Essa importância vem sendo reiterada tanto nos estudos sobre a inserção de jovens no trabalho da costura na Bolívia, quanto nos estudos sobre a denominada "diáspora boliviana"24.

\footnotetext{
${ }^{23}$ No momento da entrevista, Orlando estava de férias, na baixa temporada, visitando seus tios em Cochabamba.

${ }^{24}$ Desde o início dos anos 1980, a Bolívia vive um momento de intensa recessão econômica e início da aplicação de medidas neoliberais. Essas circunstâncias dinamizaram movimentos migratórios
} 
Em relação à inserção laboral, Samanamud ${ }^{25}$, em estudo sobre a indústria de confecção de El Alto, na Bolívia, constata a importância das relações de sociabilidade familiares para o aprendizado do ofício e para a sua inserção inicial, bem como para o estabelecimento da oficina de costura própria, seja devido aos auxílios materiais proporcionados pelos familiares, seja devido à importância da formação da "pareja" (casal) para o estabelecimento da oficina de costura própria ${ }^{26}$. Dentre os percursos apresentados, encontramos esse tipo de aprendizado desde a Bolívia no percurso de Diana que, como Orlando e Ângela, que aprenderam o ofício com os familiares nas cidades de destino, acabou por constituir-se em um ofício que os jovens pretendem carregar para a sua vida adulta.

$\mathrm{E}$, em relação às migrações internacionais bolivianas, inúmeros estudos indicam o estabelecimento de vários tipos de redes sociais, entre origens e destinos, de apoio ao projeto migratório, possibilitando o acesso a informações prévias à partida, ideias e soluções a respeito do acesso ao funcionamento institucional correspondente ao lugar de destino, recursos materiais e acolhimento inicial ${ }^{27}$. Conforme, exemplifica o trecho a seguir de Cortes sobre os migrantesbolivianos e bolivianas residentes em Buenos Aires:

A solidariedade interfamiliar característica das sociedades andinas possui um papel fundamental na integração dos bolivianos. As famílias instaladas há mais tempo nos bairros de Buenos Aires, a Charrúa, a Salada ou a Ferrere, servem de enlace à chegada de novos migrantes e dão lugar a agrupamentos de bolivianos (...). Em troca de pequenos serviços, os migrantes que residem há mais tempo na cidade alojam os recém

internos e internacionais para os seus destinos tradicionais, a Argentina (principal destino dos emigrantes bolivianos desde o século XIX) e Brasil, mas também, intensamente, para o Peru e a Venezuela, na América Latina, para os Estados Unidos, países da União Europeia (principalmente, Itália e Espanha), Israel, Japão e Austrália. Estima-se que, atualmente, em torno de $20 \%$ da população boliviana viva fora de seu país. Ver: CEPAL/CELADE/OIM. Un Examen de la Migración Internacional en la Comunidad Andina; PEREIRA, V. Vacaflores. Migración interna en Bolívia causas y consecuencias (1985-2000); HINOJOSA, Alfonso R. Procesos migratorios transnacionales en Bolivia y Cochabamba.

${ }^{25}$ SAMANAMUD, Jiovanny et alii. La configuración de las redes sociales en el microcrédito en contextos de precariedad laboral - el caso de los confeccionistas en tela de la ciudad de El Alto.

${ }^{26}$ Destaque-se que pesar de a indústria de confecção boliviana ser ainda uma indústria de confecção bastante incipiente, é a terceira maior atividade econômica do país, depois da agricultura e da atividade mineira (FRAZIER, Barbara e BRUSS, Mozhdeh. Barriers to Bolivian participation in the global apparel industry, p. 439).

27 DE LA TORRE, Leonardo e ARAMAYO, Yolanda Alfaro. La chequanchada: caminos y sendas del desarrollo em los municípios migrantes de Arbieto y Toco; DE LA TORRE, Leonardo. No llores, prenda, pronto volveré - migración, movilidad social, herida familiar y desarrollo; HINOJOSA, Alfonso R. España en el itinerario de Bolivia. Migración transnational, género y familia en Cochabamba; IDEM. Buscando la vida - familias bolivianas transnacionales en España. CORTES, Geneviève. Partir para quedarse - supervivencia y cambio en las sociedades campesinas andinas (Bolivia). 
chegados. E quando tem economias suficientes, os recém chegados se instalam em suas próprias casas e recebem, por sua vez, outras famílias. Assim perpetuam a 'cadeia migratória' (tradução própria) ${ }^{28}$.

Diferentemente dos processos migratórios analisados pelos autores citados acima, a migração boliviana vinculada ao trabalho em oficinas de costura nas cidades de destino, se organiza em torno de redes de sociabilidade específicas, as "redes de contratação", pois o auxílio recebido pelos migrantes para a realização do percurso migratório e inserção inicial na oficina de costura (que é, ao mesmo tempo, local de trabalho e de moradia) é oferecido pelos próprios donos das oficinas de costura, como parte de um acordo laboral que, em todas as 50 entrevistas, realizadas no Brasil e na Bolívia, foi negociado nas localidades de origem dessa migração.

O financiamento da migração, da alimentação e de um local de moradia nas cidades de destino concomitante ao oferecimento de um trabalho transforma completamente os processos de seletividade migratória nas regiões de origem que, em geral, franqueiam a migração apenas para aqueles em melhores condições relativas. Nessas circunstâncias, a migração para as cidades de destino das oficinas de costura bolivianas transforma-se em uma possibilidade aberta virtualmente a todos os que se disponham a aprender o ofício, não sendo necessária a mobilização de outras redes sociais, nem de recursos financeiros e nem mesmo a habilidade na costura.

Entretanto, essas facilidades têm um preço que passou a ser denominado pelos pesquisadores bolivianos e entre os próprios costureiros e costureiras de "derecho de piso". Uma espécie de relação de reciprocidade diferida, em que: o dono da oficina de costura, de mesma nacionalidade, auxilia primeiro (com o oferecimento do trabalho, migração, alimentação e moradia), o costureiro ou aprendiz retribui depois, ao chegar à cidade de destino, com sua fidelidade e com seu trabalho na oficina de costura daquele que o auxiliou.

O papel das redes de sociabilidade familiares dos jovens nesse tipo de inserção laboral nas cidades de destino tem se mostrado bastante ambivalente, pois os vínculos familiares, além de não garantirem, necessariamente, uma inserção laboral mais estável, podem legitimar situações de superexploração laboral que, por envolverem relações afetivas, tornam-se de difícil solução para os migrantes, podendo perdurar por muito tempo ${ }^{29}$. Nesse sentido, destaca-

28 Ibidem, p. 184.

${ }^{29}$ BEHERAN, FREITAS, op. cit.; CUSICANQUI, op. cit. Para aprofundar no debate a respeito dos efeitos negativos das "economias étnicas", ver: BONACICH, The other side..., op. cit.; SANDERS, Jimy e NEE, Victor. Limits of ethnic solidarity in the enclave economy; PORTES, Alejandro e SENSENBRENNER, Julia. Embeddedness and Immigration: notes on the social determinants of economic action. 
se o percurso de Ester que foi enganada e coagida a realizar uma atividade laboral que não queria realizar, em uma situação que, nos termos da OIT, pode ser caracterizada como "trabalho forçado", devido à ameaça e o caráter involuntário do trabalho realizado ${ }^{30}$. E o de Orlando que, embora não tenha sido obrigado e tenha, inclusive, aprendido um ofício que acabou por definir sua vida laboral futura,se sentia explorado pela prima, em Buenos Aires ${ }^{31}$.

Entretanto, para outros jovens, como Esteves, sua inserção laboral na costura é avaliada de maneira instrumental. Diante das escassas oportunidades laborais que esses jovens encontram e das práticas de exclusão e de discriminação que enfrentam cotidianamente, a inserção na costura aparece como única possibilidade viável, apesar de ser uma atividade desprezada por esses jovens. Nesse caso, seus interesses e expectativas enfrentam as duras limitações que o contexto em que vivem lhes impõe.

E, ainda, pudemos encontrar jovens que manifestam um reconhecimento extremamente positivo em relação às experiências formativas no âmbito familiar, que possibilitaram que se inserissem nos espaços laborais e ganhassem algum dinheiro para ajudar sua família ou ainda participar ativamente das estratégias de mobilidade social do núcleo familiar, como é o caso de Ângela e Diana. Enquanto, no caso de Ângela, trata-se, claramente, da inserção laboral em um negócio familiar (a oficina de costura de sua mãe) como parceira e responsável pela mobilidade social vislumbrada por seu núcleo familiar, no caso de Diana, graças ao ofício aprendido com o pai, na Bolívia, foi possível a inserção bem sucedida em uma oficina de costura em São Paulo que Ihe possibilitou montar uma oficina de costura em sua casa, na Bolívia, na qual trabalha junto com o seu pai.

Dessa forma, de maneira geral, as entrevistas realizadas junto aos jovens bolivianos e bolivianas nos advertem da necessidade de analisar as relações laborais, que se desenvolvem no interior das oficinas de costura, tendo em vista a heterogeneidade de situações existentes e as múltiplas formas a partir das quais os jovens vivenciam as experiências laborais das quais participam.

${ }^{30}$ De acordo com a definição deste conceito elaborada pela Organização Internacional do Trabalho (OIT), por "trabalho forçado" se entende "todo trabalho ou serviço exigido a um indivíduo sob ameaça de uma pena qualquer e para o qual o indivíduo não se oferece voluntariamente" (OIT. El costo de la coacción. Informe global con arreglo al seguimiento de la Declaración de la OIT relativa a los principios y derechos fundamentales en el trabajo, p. 7).

${ }^{31}$ Nesta verbalização de Orlando, podemos entrever de maneira bastante concreta o tipo de questão moral posta para esses jovens no trabalho em oficinas de costura de familiares: "Esmuchomejortrabajarcon gente ajena que familiar, porque hay famílias que te quierenhumillar, o que te tratan mal, a veces, por eso todo, tienes que aguantarte todo, no sabes cómoreaccionar y vos mismo te estás oprimiendo. Ahí, si es otro, dices todo, si es con familiar tienes que callarte, por eso es preferible trabajar con gente ajena" (Orlando). 
A vulnerabilidade em que, geralmente, se encontra imersa essa população migrante acaba por gerar situações de trabalho precário e/ou exploração laboral em relação às quais dificilmente conseguem se livrar. E, conforme indicamos ao longo deste artigo, as redes de parentesco e compadrio cumprem um papel preponderante na dinamização destas situações. Contudo, é importante ter em vista que, para compreender a permanência deste tipo de atividade econômica e dessa forma de organização do trabalho, é necessário considerar a presença, nessas redes, dos atores sociais dos países de destino entre os quais, cabe mencionar, as grandes marcas de roupas cuja produção se realiza nessas oficinas de costura e os responsáveis pelo controle do ingresso e permanência de pessoas em situação irregular. Para compreender profundamente o funcionamento deste tipo de atividade, que tem como protagonistas os jovens migrantes bolivianos e bolivianas, é fundamental considerar a responsabilidade e a implicação destes atores locais.

\section{Referências Bibliográficas}

ARANGO, Joaquim. Explaining Migration: a critical view. Oxford: Blackwell Publishers, 2000.

ASSIS, Gláucia de Oliveira; SASAKI, Elisa Massae. Novos migrantes do e para o Brasil: um balanço da produção bibliográfica. In CASTRO, Mary Garcia (coord.). Migrações internacionais - contribuições para políticas. Brasília: CNPD, 2001, p. 615-639.

AZEVEDO, Flávio Antônio Gomes. A presença de trabalho forçado na cidade de São Paulo - Brasil/Bolívia. Dissertação de Mestrado da Faculdade de Economia e Administração da USP (FEA/USP). São Paulo, 2005.

BASSEGIO, Luiz. A imigração latino-americana para o Brasil: o caso dos bolivianos em São Paulo. Cadernos do CEAS, n. 214, 2004, p. 51-59.

BASTIA, Tanja. From mining to garment workshops - bolivian migrants in Buenos Aires. Journal of Ethnic and Migration Studies, v. 33, n. 4, 2007, p. 655-669.

BASTIA, Tanja; McGRATH. Temporality, migration and unfreelabour: migrant garment workers. Manchester Papers in Political Economy. Universidade de Manchester, 2011. BEHERAN, Mariana. Niños, niñas y jóvenes bolivianos y bolivianas en la ciudad de Buenos Aires. Escolaridad y experiencias formativas en el ámbito familiar. Estudios Migratorios Latinoamericanos, n. 67, 2009.

- Intersecciones entre trayectorias migratorias, escolares y laborales de jóvenes bolivianos y paraguayos residentes en un barrio del sur de la ciudad de Buenos Aires. In NOVARO, Gabriela (org.). La interculturalidad en debate. Experiencias formativas y procesos de identificación en niños indígenas y migrantes. Buenos Aires: Editorial Biblos, 2011.

BEHERAN, Mariana; FREITAS, Patricia T. Trajetórias migratórias e inserção laboral de jovens migrantes bolivianos (as) em oficinas de costura nas cidades de São Paulo e 
Buenos Aires. In PEREIRA, Gloria S.; PEREIRA, José R. Migração e Globalização um olhar interdisciplinar. Curitiba: Editora CRV, 2011, p. 265-292.

BENENCIA, Roberto. El infierno del trabajo esclavo - la contracara de las "exitosas" economías étnicas. Avá, n. 15, 2009.

BONACICH, Edna. A theory of middleman minorities. American Sociological Review, v. 38, n. 5, p. 583-594, 1973.

. The other side of ethnic entrepreneurship: a dialogue with Waldinger, Aldrich, Ward and associates. International Migration Review, v. 27, n. 3, 1993.

BONACICH, Edna; APPELBAUM, Richard. The return of the sweatshop. In KLENIEWSKI, Nancy. Cities and Society. Oxford: Blackwell Publishing, 2005, p. 127-143.

BONFIGLIO, Juan; SALVIA, Agustín; TINOBRAS, Cecilia; VAN RAAP, Vanina. Educación y trabajo. Un estudio sobre las oportunidades de inclusión de los jóvenes tras cuatro años de recuperación económica. In SALVIA, Agustín (org.). Jóvenes promesas. Trabajo, educación y exclusión social de jóvenes pobres en la Argentina. Buenos Aires: Miño y Dávila, 2008.

BUECHLER, Simone. Sweating it in the Brazilian Garment Industry: Bolivian workers and global economic forces in São Paulo. Metropolitan Studies, New York University, 2003.

CACHÓN RODRÍGUEZ, Lorenzo. Inmigrantes jóvenes en España. Sistema Educativo y mercado de trabajo. Madrid: Edición Injuve, 2003.

CEPAL/CELADE/OIM. Un Examen de la Migración Internacional en la Comunidad Andina. Proyecto Sistema de Información sobre Migración Internacional en los Países de la Comunidad Andina (SIMICA). Santiago do Chile, 1999.

CORTES, Geneviève. Partir para quedarse - supervivencia y cambio en las sociedades campesinas andinas (Bolivia). Equador: Plural Editores, 2004.

CYMBALISTA, Renato; XAVIER, lara Rolnik. A Comunidade boliviana em São Paulo: definindo padrões de territorialidade. Cadernos Metrópole, n. 17, 2007.

CRUZ-MOREIRA, Juan Ricardo. Industrial upgrading nas cadeias produtivas globais: reflexões a partir das indústrias têxtil e do vestuário de Honduras e do Brasil. 2003. Tese de Doutorado - Universidade de São Paulo, São Paulo, 2003.

CUSICANQUI, Silvia Rivera et alii. De chuequistas y overlockas - uma discussión en torno a los talleres textiles. Buenos Aires: Tinta Limón, 2011.

DE LA TORRE, Leonardo. No llores, prenda, pronto volveré - migración, movilidad social, herida familiar y desarrollo. La Paz: PIEB, IFEA, UCB, 2006.

DE LA TORRE, Leonardo; ARAMAYO, Yolanda Alfaro. La chequanchada: caminos y sendas del desarrollo en los municipios migrantes de Arbieto y Toco. La Paz: CESU \& PIEB, 2007.

FILMUS, Daniel; MIRANDA, Ana; OTERO, Analía. La construcción de trayectorias laborales entre los jóvenes egresados de la escuela secundaria. In Jacinto, Claudia (comp.) ¿Educar para qué trabajo? Discutiendo rumbos en América Latina. Buenos Aires: La Crujía, 2004.

FRAZIER, Barbara; BRUSS, Mozhdeh. Barriers to Bolivian participation in the global 
apparel industry. Journal of Fashion Marketing and Management, v. 8, n. 4, 2004, p. 437-451.

FREITAS, Patrícia. Projeto Costura: percursos sociais de trabalhadores migrantes, entre origens e destinos. Tese de Doutorado. Instituto de Filosofia e Ciências Humanas da UNICAMP, 2014.

FREITAS, Patrícia T.; BAENINGER, Rosana. Imigração e cidade: origens e territórios da imigração boliviana para a cidade de São Paulo. In BAENINGER, Rosana (org.). População e cidades - subsídios para o planejamento e as políticas sociais. Campinas: UNFPA, Nepo, Unicamp, 2010.

GALLART, María Antonia. Educación y empleo en el Gran Buenos Aires, 1991-1999. Buenos Aires: Serie Fondo de Investigaciones, Programa MECOVI, 2001.

GARCIA, O. L. Avaliação da competitividade da indústria têxtil brasileira. Tese de Doutorado, Instituto de Economia da UNICAMP, Campinas, SP, 1994.

GARCIA, Renato; CRUZ-MOREIRA, Juan. O Complexo Têxtil Vestuário: um cluster resistente. In AMITRANO, Claudio Roberto et alii. Caminhos para o centro - estratégias de desenvolvimento para a região central de São Paulo. São Paulo: Emurb, 2004.

GLICK SCHILLER, Nina; BASH, Linda; BLANC, Cristina Szanton. From immigrant to transmigrant: theorizing transnational migration. Anthropological Quarterly, v. 68, n. 1, p. 48-63, 1995.

GREEN, Nancy. Du sentier à la $7^{a}$ avenue - la confection et les immigrés, Paris-New York (1880-1980). Paris: Éditions du Seuil, 1998.

GORINI, Ana Paula Fontenelle. Panorama do setor têxtil no Brasil e no mundo: reestruturação e perspectivas. BNDES Setorial, n. 12, 2000.

HIRATUKA, Célio; GARCIA Renato de Castro. Impactos da abertura comercial sobre a dinâmica da indústria têxtil brasileira. Leituras de Economia Política, Ano 1, n. 1, set. 1995, p. 83-105.

HINOJOSA, Alfonso R. España en el itinerario de Bolivia. Migración transnational, género y familia en Cochabamba. In NOVICK, Susana (org.). Las migraciones en América Latina. Buenos Aires: Catálogos, 2008, p. 93-112.

. Buscando la vida - familias bolivianas transnacionales en España. La Paz: PIEB, CLACSO, 2009.

. Procesos migratorios transnacionales en Bolivia y Cochabamba. Cuaderno de Refléxion, Programa de Cooperación Interuniversitaria, UMSS-CIUF: Cochabamba, 2012.

JACINTO, Claudia. Políticas públicas, trayectorias y subjetividades en torno a la transición laboral de los jóvenes. In PEREZ SOSTO, Guillermo (ed.). El Estado y la reconfiguración de las protecciones sociales. Buenos Aires: Instituto Torcuato Di Tella y Siglo XXI, 2008.

KADLUBA, Ruth Camacho. A imigração na cidade de São Paulo - integração dos imigrantes na cidade como forma de combate à pobreza - URB AL Rede 10. São Paulo: Secretaria Especial para Participação e Parceria, Instituto Uniemp - Fórum Permanente das Relações Universidade /Empresa e Comunidade Européia, 2007. 
LIGHT, Ivan; GOLD, Steven. Ethnic Economies. California: Academic Press, 2000.

LUPATINI, Márcio P. As transformações produtivas na indústria têxtil do vestuário e seus impactos sobre a distribuição territorial da produção e a divisão do trabalho industrial. Dissertação de Mestrado. Instituto de Geociências da UNICAMP, 2004.

MA MUNG, Emmanuel. Le point de vue de l'autonomie dans l'étude des migrations internationales: penser de l'intérieur lês phenomènes de mobilité. In DUREAU, François; HILY, Marie Antoniette. Les mondes de la mobilité. Rennes: Presses Univertiaire de Rennes, 2009, p. 25-38.

MARTíNEZ, Jorge. Migración internacional de jóvenes de América Latina y el Caribe. In BURAK, Solum Donas (org.). Adolescencia y Juventud. Cartago: Libro Universitario Regional, 2001.

MONTERO, Jeronimo. Neoliberal fashion: the political economy of sweatshops in Europe and Latin America. Tese de Doutorado, Durhan University, 2011.

OIT. El costo de la coacción. Informe global con arreglo al seguimiento de la Declaración de la OIT relativa a los principios y derechos fundamentales en el trabajo. Conferencia Internacional del Trabajo. 98ª Reunión, Ginebra, 2009.

PALPACUER, Florence. Subcontracting networks in the New York City garment industry: changing characteristics in a global era. In GEREFFI, Gary et alii (ed.). Free trade and uneven development: the north American apparel industry after NAFTA. Philadelphia: Temple UniversityPress, 2002.

PEDONE, Claudia. 'Lo de migrar me lo pensaría con calma': representaciones sociales de jóvenes en torno al proyecto migratorio familiar. In PEDREÑO CÁNOVAS, Andrés (org.). Tránsitos migratorios: contextos transnacionales y proyectos familiares en las migraciones actuales. Murcia: Universidad de Murcia-AECI, 2010.

PEDREÑO CÁNOVAS, Andrés; CASTELLANOS ORTEGA, Mari Luz. En busca de un lugar en el mundo. Itinerarios formativos-laborales de los hijos de familias inmigrantes en el campo murciano. In Grupo Interdisciplinario de Investigador@s Migrantes (coord.). Familias, niños, niñas y jóvenes migrantes. Rompiendo estereotipos. Madrid: IEPALA EDITORIAL, 2010.

PEREIRA, V. Vacaflores. Migración interna en Bolívia - causas y consecuencias (1985 - 2000). La Paz: CEF - Plural Editor, 2004.

POTOT, Swanie. Circulation et reseaux de migrants roumains - une contribution a I'etude des nouvelles mobilites en Europe, 2003. Tese de doutorado na Université de Nice - Sophia Antipolis.

PORTES, Alejandro; SASSEN-KOOB, Saskia. Making it underground: comparative material on the informal sector in western market economies. American Journal of Sociology, v. 93, 1987, p. 30-61.

PORTES, Alejandro; SENSENBRENNER, Julia. Embeddedness and Immigration: notes on the social determinants of economic action. American Journal of Sociology, v. 98, n. 6, 1993.

ROSS, Robert J. S. The new sweatshops in the United States: how new, how real, how 
many and why? In GEREFFI, Gary et alii (ed.). Free trade and uneven development: the north American apparel industry after NAFTA. Philadelphia: TempleUniversity Press, 2002.

SANDERS, Jimy; NEE, Victor. Limits of ethnic solidarity in the enclave economy. American Sociological Review, v. 52, 1987, p. 745-73.

SILVA, Sidney A. Costurando sonhos - trajetória de um grupo de imigrantes bolivianos em São Paulo. São Paulo: Paulinas, 1997.

. Bolivianos em São Paulo: entre o sonho e a realidade. Estudos Avançados, v. 20, n. 57, 2006.

SALVIA, Agustín; TUÑON, lanina. Los jóvenes trabajadores frente a la educación, el desempleo y el deterioro social en la Argentina. Buenos Aires: Fundación Friedrich Ebert, 2003.

SAMANAMUD, Jiovanny et alii. La configuración de las redes sociales en el microcrédito en contextos de precariedad laboral - el caso de los confeccionistas en tela de la ciudad de El Alto. La Paz: PIEB, 2003.

TRPIN, Verónica. Aprender a ser chilenos. Identidad, trabajo y residencia de migrantes en el Alto Valle de Río Negro. Buenos Aires: Antropofagia, 2004.

\section{Abstract}

\section{Family life and labor of young migrants in the industry of confection}

This article addresses the social paths of young Bolivians who at some point in their lives migrated to work in the small sewing shops of their countrymen in the cities of São Paulo, Brazil, and Buenos Aires, Argentina. Based on the doctoral research titled "Sewing Project", the analysis seeks to address the various meanings attributed to the role of family in the young Bolivians' forms of integration, circulation and departure from this labor in the cities of destination and in Bolivia.

Keywords: bolivian migration, youth, clothing industry, work.

Recebido para publicação em 16/03/2014.

Aceito para publicação em 20/05/2014. Received for publication on March, 16 ${ }^{\text {th }}, 2014$. Accepted for publication on May, 20 2014. 